\title{
Post-operative outcomes of open and laparoscopic gastrectomy for gastric cancer: A single-center experience
}

\author{
Bahri Çakabay \\ Department of General Surgery, Gazi Yasargil Training and Research Hospital, Diyarbakir, Turkey
}

\begin{abstract}
Introduction: Laparoscopy-assisted distal gastrectomy (LADG) has rapidly been gaining popularity. However, there is only limited evidence regarding its oncological safety. The aim of this study is to identify the effects of laparoscopy on post-operative complications and on the total number of excised and metastatic lymph nodes in cases with + D2 lymph node dissection due to gastric cancer.

Materials and Methods: 40 consecutive patients, who underwent gastrectomy and routine D2 lymph node dissection in our clinic between March 2019 and March 2020, were included in the study. The patients were divided into two groups as per the technique applied; open surgery (Group 1) and laparoscopic surgery (Group 2). Demographic characteristics, intra-operative time, need for blood transfusion, post-operative complications, and histopathological features were compared between the groups.

Results: The results of the study revealed that Group 1 had longer hospital stay periods $(p=0.03)$ but other clinical features like intra-operative and post-operative complication rates were similar in both groups. Pathology results of the groups also showed no statistically significant difference in terms of the number of excised lymph nodes, the number of metastatic lymph nodes, and the ratio of metastatic lymph nodes to excisedlymph nodes.
\end{abstract}

Conclusion: Laparoscopic surgery can be performed safely and may be recommended as a possible alternative to open surgery. The study emphasized a faster post-operative recovery as the main benefit of laparoscopic gastrectomy.

Keywords: Gastrectomy; gastric Cancer; laparoscopy.

\section{Introduction}

Gastric cancer has the fourth highest incidence among cancers worldwide and is the second most common cause of cancer-related mortality. It accounts for $8 \%$ of total cancer-related mortality globally while accounting for $10 \%$ of annual cancer-related mortality cases. ${ }^{[1,2]}$ Surgery remains the single therapeutic method in spite of the developments in goal-directed therapy and chemoradiotherapy. Local or extended lymphadenectomy together with the total excision of macroscopic and microscopic malign lesions represent the optimal treatment of choice for localized resectable gastric cancer. ${ }^{[3]}$ 
Laparoscopy-assisted distal gastrectomy (LADG) has been adopted rapidly worldwide since its inception in $1994 .^{[4]}$ Many studies that compared laparoscopic and open surgery have confirmed that minimally invasive laparoscopic surgery had obvious advantages. ${ }^{[5-7]}$ Moreover there are also numerous other studies that have reported that there was no difference between laparoscopic and open surgery as per long-term outcomes for locally advanced gastric cancer. ${ }^{[8-10]}$

This study investigated the intra-operative and post-operative clinical outcomes according to the surgical technique used in gastric cancer patients with distal gastrectomy and D2 lymph node dissection.

\section{Materials and Methods}

\section{The Patients}

The data of patients, who had undergone gastrectomy and routine D2 lymph node dissection at Diyarbakır University of Health Sciences, Gazi Yaşargil Training and Research Hospital's General Surgery Clinic between March 2019 and March 2020 because of gastric cancer, were retrospectively analyzed. All the patients were diagnosed with gastric adenocarcinoma confirmed by gastroscopic biopsy. All the patients received computerized tomography for pre-operative staging. Exclusion criteria included patients with palliative resection, conversion to open surgery from laparoscopy, and insufficient health file data.

60 patients had undergone surgery within this period having been diagnosed with gastric cancer. 40 of these patients who met the inclusion criteria were included in the study.

\section{Grouping}

The patients were categorized into two groups as per the technique used: those with open surgery (Group 1) and those with laparoscopic surgery (Group 2).

\section{Data}

Pre-operative data on the patients' ages, sexes, diabetes mellitus (DM), hypertension (HT), chronic obstructive pulmonary disease (COPD), chronic renal failure, pre-operative laboratory results, and history of smoking were retrospectively collected. Intra-operative time (minutes), blood transfusions during the surgery, and period of hospitalization (days) were recorded as well.

Mortality during the first 30 days of follow-up during the post-operative period was defined as surgical mortality, while surgical complications that developed during the same period were defined as morbidity. Post-operative complications were ranked according to the ClavienDindo Classification. ${ }^{[1]]}$

Tumor size $(\mathrm{mm})$, distal border $(\mathrm{mm})$, proximal border $(\mathrm{mm})$, invasion depth, number of lymph nodes excised, number of metastatic lymph nodes detected, and the lymphovascular and perineural invasion presence of the tumor were recorded based on pathology reports. The ratio of metastatic lymph nodes to the excised lymph nodes (LNR) was categorized into four groups as LNR: 0, $0<$ LNR $\leq 0.1,0.1<\mathrm{LNR} \leq 0.4, \mathrm{LNR}>0.4$. The pathological staging of the tumor was performed according to the 7th edition of the American Joint Committee on Cancer's (AJCC) TNM staging system. ${ }^{[12]}$

I. The primary endpoint of the study was to investigate whether laparoscopic surgery posed technical challenges and caused post-operative complications.

II. The secondary endpoint of the study was to reveal the degree to which laparoscopic surgery affected pathology results.

\section{Statistical Analysis}

SPSS (Statistical Package for Social Sciences, Inc., Chicago, IL, USA) for Windows 21.0 software was used to perform statistical analyses of the data collected within the scope of the study. The mean, minimum, maximum, and standard deviation values were calculated for the data collected from the patients included in the study. Further the Kolmogorov-Smirnov test was used to control the distribution of data while group Student's t-test was used to analyze data with normal distribution. Group comparisons of non-parametric data were performed by the Mann-Whitney U test. Categorical groups were compared by the chi-squared test. $\mathrm{P}<0.05$ was set as statistically significant.

\section{Results}

\section{Demographic Characteristics}

4 patients with palliative gastrectomy, 4 patients with conversion from laparoscopy to open surgery, 10 patients with insufficient health file data, and 2 patients who did not receive D2 lymph node dissection between March 2019 and March 2020 were excluded from the study. Finally the data of 40 patients who underwent gastrectomy and D2 lymph 
node dissection because of gastric cancer were analyzed within the scope of the study. While Group 1 covering open surgery patients had 22 patients, Group 2 covering laparoscopic surgery patients had 18 patients. The clinical characteristics of the patients are summarized in Table 1.

\section{Intraoperative Features and Post-operative Complications}

The results of the study revealed no difference between the groups in terms of intra-operative time and need for blood transfusion. No mortality was observed within the first 30 post-operative days in either of the groups. The period of hospitalization was found to be higher in Group 1 $(\mathrm{p}=0.03)$. Table 2 presents intra-operative features, surgical and non-surgical post-operative complications. Table 3 summarizes the comparison of complications according to the Clavian-Dindo Classification.

\section{Pathology Results}

No difference was found between the groups in terms of tumor size, the number of total and metastatic lymph nodes excised. Table 4 presents the pathological characteristics of the tumors (Table 4).

\section{Discussion}

Gastric cancer (GC) remains one of the most common and deadly malignities worldwide. ${ }^{[2,11,12]}$ Adequate lymphadenectomy and surgical resection continue to be the cornerstone and foundation of curative treatment for resectable GC patients. ${ }^{[13,14]}$ Open gastrectomy (OG) has long been the surgical modality of choice worldwide. Yet it has been associated with significant morbidity. Laparoscopic surgeons have been sparing no efforts to alter clinical practice that would minimize surgical trauma. Laparoscopic gastrectomy (LG) has such potential benefits as reducing post-operative complications and accelerating healing. ${ }^{[15]}$

Table 1. Demographic features of the patients according to the groups

\begin{tabular}{|c|c|c|c|}
\hline & Group $1(n=22)$ & Group $2(n=18)$ & $\mathbf{p}$ \\
\hline Age (mean $\pm S D)$ & $60.7 \pm 11.3$ & $64.2 \pm 11.3$ & 0.934 \\
\hline \multicolumn{4}{|l|}{ Sex, n (\%) } \\
\hline Male & $17(77.3)$ & $10(55.6)$ & 0.145 \\
\hline Female & $5(22.7)$ & $8(44.4)$ & \\
\hline \multicolumn{4}{|c|}{ Laboratory results (mean $\pm S D$ ) } \\
\hline Hematocrit & $36.3 \pm 6.4$ & $35.03 \pm 4.8$ & 0.424 \\
\hline Albumin & $3.8 \pm 0.6$ & $3.7 \pm 0.4$ & 0.078 \\
\hline CEA & $2.2 \pm 2.7$ & $4.2 \pm 4.6$ & 0.051 \\
\hline CA 19-9 & $124 \pm 435$ & $24 \pm 49$ & 0.126 \\
\hline CA 125 & $45.5 \pm 91$ & $36 \pm 65$ & 0.845 \\
\hline \multicolumn{4}{|l|}{ Comorbidity, n (\%) } \\
\hline DM & $5(22.7)$ & $4(22.2)$ & 0.970 \\
\hline COPD & $6(27.3)$ & $3(16.7)$ & 0.424 \\
\hline CRF & 0 & $1(5.6)$ & 0.263 \\
\hline CAD & $4(18.2)$ & $2(11.1)$ & 0.533 \\
\hline $\mathrm{HT}$ & $5(22.7)$ & $7(38.9)$ & 0.267 \\
\hline History of smoking, $\mathrm{n}(\%)$ & $10(45.5)$ & $3(16.7)$ & 0.053 \\
\hline Weight loss (>10\%), n (\%) & $7(31.8)$ & $6(33.3)$ & 0.919 \\
\hline \multicolumn{4}{|l|}{ ASA, $n(\%)$} \\
\hline 1 & 0 & 0 & 0.131 \\
\hline 2 & $7(31.8)$ & $10(55.6)$ & \\
\hline 3 & $15(68.2)$ & $8(44.4)$ & \\
\hline
\end{tabular}

CEA: Carcinoembryonic antigen; CA 19-9: Carbohydrate antigen 19-9; CA 125: Carbohydrate antigen 125; DM: Diabetes mellitus; COPD: Chronic obstructive pulmonary disease; CRF: Chronic renal failure; CAD: Coronary artery disease; HT: Hypertension; ASA: American Society of Anesthesiologists. 
Table 2. Intra-operative features and post-operative complications

\begin{tabular}{|c|c|c|c|}
\hline & Group 1 & Group 2 & $\mathbf{p}$ \\
\hline Intra-operative time (mean $\pm S D$ ) & $140 \pm 75$ & $181 \pm 130$ & 0.498 \\
\hline Intra-operative blood transfusion, n (\%) & $5(22.7)$ & $4(22.2)$ & 0.970 \\
\hline \multicolumn{4}{|l|}{ Abdominal complication, n (\%) } \\
\hline Surgical site infection & $5(22.7)$ & $3(16.7)$ & 0.634 \\
\hline Abdominal abscess & 0 & 0 & \\
\hline Anastomotic fistula & 0 & 0 & \\
\hline Intraabdominal hemorrhage & $3(13.6)$ & $1(5.6)$ & 0.397 \\
\hline Chylous ascites & $1(4.5)$ & $1(5.6)$ & 0.884 \\
\hline Evisceration or eventration & $1(4.5)$ & 0 & 0.360 \\
\hline Pancreatic fistula & 0 & $1(5.6)$ & 0.263 \\
\hline \multicolumn{4}{|l|}{ Systemic complication, $\mathrm{n}(\%)$} \\
\hline Atelectasis & $1(4.5)$ & $3(16.7)$ & 0.204 \\
\hline Pneumonia & $3(13.3)$ & $4(22.2)$ & 0.477 \\
\hline Renal failure & $2(9.1)$ & $1(5.6)$ & 0.673 \\
\hline ARDS & 0 & 0 & \\
\hline Catheter infection & $2(9.1)$ & 0 & 0.189 \\
\hline Period of Hospitalization (mean $\pm S D$ ) & $6.3 \pm 1.5$ & $5.05 \pm 0.87$ & $0.03^{x}$ \\
\hline In-hospital Mortality, n (\%) & 0 & 0 & \\
\hline
\end{tabular}

Table 3. The comparison of complications according to the clavian-dindo classification

\begin{tabular}{lccc} 
& $\begin{array}{c}\text { Group 1 } \\
\mathbf{n}(\%)\end{array}$ & $\begin{array}{c}\text { Group 2 } \\
\mathbf{n}(\%)\end{array}$ & $\mathbf{p}$ \\
\hline $\begin{array}{l}\text { No complications } \\
\text { Clavian-dindo }\end{array}$ & $11(50)$ & $9(50)$ & 0.670 \\
classification & & & \\
I & $2(9.1)$ & 0 & \\
II & $5(22.7)$ & $5(27.8)$ & \\
III & $2(9.1)$ & $3(16.7)$ & \\
IV & $2(9.1)$ & $1(5.6)$ & \\
V & 0 & 0 &
\end{tabular}

Minimally invasive therapy has become a fundamental management strategy for early GC. ${ }^{[16]}$ Randomized and prospective evidence, which supported the fact that LG's safety and oncological outcomes were not poor, has constantly and actively been produced by laparoscopic researchers in Asia where LG has gained rapid popularity. ${ }^{[17-19]}$

Laparoscopic resection was initially recommended especially for the treatment of early GC with distal localization in the stomach. ${ }^{[16]} \mathrm{A}$ randomized controlled study by
Korean researchers (2010), ${ }^{[20]}$ compared laparoscopic distal gastrectomy (LDG) with open distal gastrectomy (ODG) for the treatment of cTNM stage I gastric adenocarcinoma in 342 patients. The results of the study found no significant difference between the groups in terms of post-operative complication ( $11 \%$ vs. $15 \%$ ) or mortality rates ( $1 \%$ vs. $0 \%)$. Moreover, two other studies conducted in Korea ${ }^{[21,}$ ${ }^{22]}$ ascertained similar and even significantly lower rates of overall and wound site complications. Laparoscopic surgery has become an acceptable method for locally advanced GC following further studies as well. ${ }^{[23,24]}$

Operative time, need for blood transfusion and the number of excised lymph nodes were identified as surgical challenges within the scope of our study. No difference, however, was found between the groups. Intra-abdominal and systemic complications were designated as postoperative complications but no difference was found between the groups.

Surgeons in Japan have been routinely been performing extended lymphadenectomy (D2). ${ }^{[7]}$ The National Comprehensive Cancer Network (NCCN) recommended in its latest panel that perigastric and celiac axis localized lymph nodes (D2) should be excised on the condition that at least 
Table 4. Pathologic features

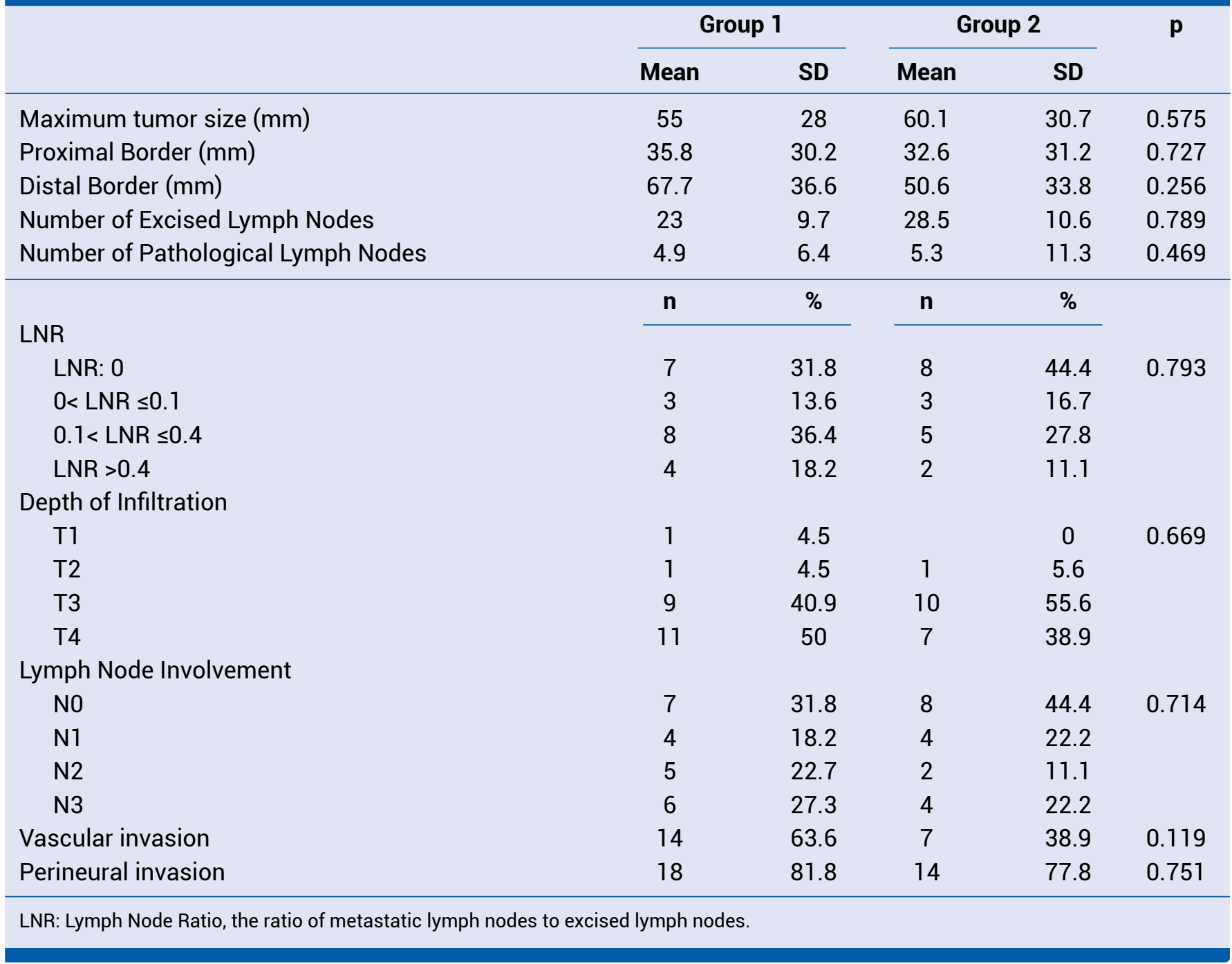

15 lymph nodes be harvested. ${ }^{[25-27]}$ The German Gastric Cancer Study put forth that if the number of excised lymph nodes was more than 25 it would be called D2 dissection, while the procedure would be referred to as D1 dissection if the number was between 15 to 25 , and as radical surgery if less than 15 lymph nodes were dissected. ${ }^{[28]} \mathrm{A}$ prospective Italian study ${ }^{[29]}$ also assessed LG versus OG for locally advanced GC. The authors of the study did not find any significant difference between the LG and OG groups in terms of 5-year cancer-related mortality rates (50\% vs. $52 \%$ ) and 5-year overall mortality rates (55\% vs. 56\%). Accordingly the authors could have compared cancer-related and overall survival rates. The Chinese database, ${ }^{[15]}$ on the other hand, found that the LG group had a significantly higher number of dissected lymph nodes at stations 11 and 12. The researchers, however, did not find any statistically significant difference between the two groups in terms of the therapeutic index at each LN station.

The results of our study revealed that 15 and higher number of lymph nodes were excised from 38 out of 40 patients (95\%). When the mean number of excised lymph nodes was assessed, it was found that this figure was 23 in OG while it was 28.5 in LG but there was no statistically significant difference between the two groups. Moreover, no statistically significant difference was found between the two groups in terms of the number of metastatic lymph nodes and the ratio of metastatic lymph nodes to the number of excised lymph nodes.

Our study had a couple of important limitations. Our study was a retrospective observational one conducted with a limited number of patients that, in turn, led to certain limitations in its design.

We suggest that laparoscopy does not affect the total num- 
ber of excised and metastatic lymph nodes in gastric cancer surgery. Moreover it does not lead to an increase complication rates. We, therefore, believe that centers with laparoscopic experience should neither be concerned about not being able to excise adequate number of lymph nodes nor about high complication rates in laparoscopic gastric cancer procedures. Nevertheless prospective studies with a wide population are needed for clearer results.

\section{Disclosures}

Peer-review: Externally peer-reviewed.

Conflict of Interest: None declared.

\section{References}

1. Guggenheim DE, Shah MA. Gastric cancer epidemiology and risk factors. J Surg Oncol 2013;107:230-6. [CrossRef]

2. Siegel RL, Miller KD, Jemal A. Cancer statistics, 2018. CA Cancer J Clin 2018;68:7-30. [CrossRef]

3. Saka M, Morita S, Fukagawa T, Katai H. Present and future status of gastric cancer surgery. Jpn J Clin Oncol 2011;41:307-13. [CrossRef]

4. Kitano S, Iso Y, Moriyama M, Sugimachi K. Laparoscopy-assisted Billroth I gastrectomy. Surg Laparosc Endosc 1994;4:146-8.

5. Lee $\mathrm{JH}$, Han HS, Lee $\mathrm{JH}$. A prospective randomized study comparing open vs laparoscopy-assisted distal gastrectomy in early gastric cancer: early results. Surg Endosc 2005;19:168-73. [CrossRef]

6. Kodera Y, Fujiwara M, Ohashi N, Nakayama G, Koike M, Morita $S$, et al. Laparoscopic surgery for gastric cancer: a collective review with meta-analysis of randomized trials. J Am Coll Surg 2010;211:677-86. [CrossRef]

7. Kitano S, Shiraishi N, Fujii K, Yasuda K, Inomata M, Adachi Y. A randomized controlled trial comparing open vs laparoscopyassisted distal gastrectomy for the treatment of early gastric cancer: an interim report. Surgery 2002;131:S306-11. [CrossRef]

8. Song J, Lee HJ, Cho GS, Han SU, Kim MC, Ryu SW, et al. Recurrence following laparoscopy-assisted gastrectomy for gastric cancer: a multicenter retrospective analysis of 1,417 patients. Ann Surg Oncol 2010;17:1777-86. [CrossRef]

9. Shuang J, Qi S, Zheng J, Zhao Q, Li J, Kang Z, et al. A casecontrol study of laparoscopy-assisted and open distal gastrectomy for advanced gastric cancer. J Gastrointest Surg 2011;15:57-62. [CrossRef]

10. Scatizzi M, Kröning KC, Lenzi E, Moraldi L, Cantafio S, Feroci F. Laparoscopic versus open distal gastrectomy for locally advanced gastric cancer: a case-control study. Updates Surg 2011;63:17-23. [CrossRef]

11. Chen W, Zheng R, Baade PD, Zhang S, Zeng H, Bray F, et al. Cancer statistics in China, 2015. CA Cancer J Clin 2016;66:115-32. [CrossRef]

12. Torre LA, Bray F, Siegel RL, Ferlay J, Lortet-Tieulent J, Je- mal A. Global cancer statistics, 2012. CA Cancer J Clin 2015;65:87-108. [CrossRef]

13. Huang L, Wei ZJ, Li TJ, Jiang YM, Xu AM. A prospective appraisal of preoperative body mass index in D2-resected patients with non-metastatic gastric carcinoma and Siewert type II/III adenocarcinoma of esophagogastric junction: results from a large-scale cohort. Oncotarget 2017;8:6816579. [CrossRef]

14. Zhang JW, Huang L, Xu AM. Preoperative monocyte-lymphocyte and neutrophil-lymphocyte but not platelet-lymphocyte ratios are predictive of clinical outcomes in resected patients with non-metastatic Siewert type II/III adenocarcinoma of esophagogastric junction: a prospective cohort study (the AMONP corhort). Oncotarget 2017;8:57516- 27. [CrossRef]

15. Li HJ, Huang L, Li TJ, Su J, Peng LR, Liu W. Short-Term Outcomes of Single-Incision Versus Conventional Laparoscopic Surgery for Colorectal Diseases: Meta-Analysis of Randomized and Prospective Evidence. J Gastrointest Surg 2017;21:1931-45. [CrossRef]

16. Japanese Gastric Cancer Association. Japanese gastric cancer treatment guidelines 2014 (ver. 4). Gastric cancer: official journal of the International Gastric Cancer Association and the Japanese Gastric Cancer Association 2017;20:1-19.

17. Zeng YK, Yang ZL, Peng JS, Lin HS, Cai L. Laparoscopy-assisted versus open distal gastrectomy for early gastric cancer: evidence from randomized and nonrandomized clinical trials. Ann Surg 2012;256:39-52. [CrossRef]

18. Viñuela EF, Gonen M, Brennan MF, Coit DG, Strong VE. Laparoscopic versus open distal gastrectomy for gastric cancer: a meta-analysis of randomized controlled trials and highquality nonrandomized studies. Ann Surg 2012;255:446-56.

19. Hayashi H, Ochiai T, Shimada H, Gunji Y. Prospective randomized study of open versus laparoscopy-assisted distal gastrectomy with extraperigastric lymph node dissection for early gastric cancer. Surg Endosc 2005;19:1172-6. [CrossRef]

20. Kim HH, Hyung WJ, Cho GS, Kim MC, Han SU, Kim W, et al. Morbidity and mortality of laparoscopic gastrectomy versus open gastrectomy for gastric cancer: an interim report--a phase III multicenter, prospective, randomized Trial (KLASS Trial). Ann Surg 2010;251:417-20. [CrossRef]

21. Hu Y, Huang C, Sun Y, Su X, Cao H, Hu J, et al. Morbidity and Mortality of Laparoscopic Versus Open D2 Distal Gastrectomy for Advanced Gastric Cancer: A Randomized Controlled Trial. J Clin Oncol 2016;34:1350-7. [CrossRef]

22. Kim W, Kim HH, Han SU, Kim MC, Hyung WJ, Ryu SW, et al; Korean Laparo-endoscopic Gastrointestinal Surgery Study (KLASS) Group. Decreased Morbidity of Laparoscopic Distal Gastrectomy Compared With Open Distal Gastrectomy for Stage I Gastric Cancer: Short-term Outcomes From a Multicenter Randomized Controlled Trial (KLASS-01). Ann Surg 2016;263:28-35. [CrossRef]

23. Cai J, Wei D, Gao CF, Zhang CS, Zhang H, Zhao T. A prospective randomized study comparing open versus laparoscopyassisted D2 radical gastrectomy in advanced gastric cancer. Dig Surg 2011;28:331-7. [CrossRef] 
24. Lin JX, Huang CM, Zheng CH, Li P, Xie JW, Wang JB, et al. Is All Advanced Gastric Cancer Suitable for Laparoscopy-Assisted Gastrectomy With Extended Lymphadenectomy? A CaseControl Study Using a Propensity Score Method. Ann Surg Oncol 2016;23:1252-60. [CrossRef]

25. Schwarz RE, Smith DD. Clinical impact of lymphadenectomy extent in resectable gastric cancer of advanced stage. Ann Surg Oncol 2007;14:317-28. [CrossRef]

26. Songun I, Putter H, Kranenbarg EM, Sasako M, van de Velde CJ. Surgical treatment of gastric cancer: 15-year followup results of the randomised nationwide Dutch D1D2 trial. Lancet Oncol 2010;11:439-49. [CrossRef]
27. Karpeh MS, Leon L, Klimstra D, Brennan MF. Lymph node staging in gastric cancer: is location more important than Number? An analysis of 1,038 patients. Ann Surg 2000;232:36271. [CrossRef]

28. Siewert JR, Böttcher K, Stein HJ, Roder JD. Relevant prognostic factors in gastric cancer: ten-year results of the German Gastric Cancer Study. Ann Surg 1998;228:449-61. [CrossRef]

29. Sica GS, laculli E, Biancone L, Di Carlo S, Scaramuzzo R, Fiorani $\mathrm{C}$, et al. Comparative study of laparoscopic vs open gastrectomy in gastric cancer management. World J Gastroenterol 2011;17:4602-6. [CrossRef] 